\title{
Effect of curing Helicobacter pylori infection on intragastric acidity during treatment with ranitidine in patients with duodenal ulcer
}

\author{
J Labenz, B Tillenburg, U Peitz, E Verdú, M Stolte, G Börsch, A L Blum
}

\begin{abstract}
Background-In patients with duodenal ulcer cure of Helicobacter pylori infection resulted in a pronounced decrease in intragastric pH during treatment with omeprazole.

Aim-To test the hypothesis that treatment of $H$ pylori adversely affects the $\mathrm{pH}$ response to ranitidine.

Patients-Eighteen patients with duodenal ulcer who were infected with $H$ pylori were studied.

Methods-Twenty four hour pH recordings were performed during treatment with ranitidine $(300 \mathrm{mg})$ at night before and four to six weeks after cure of $H$ pylori infection. Presence of $H$ pylori was assessed by a rapid urease test, culture, histology, and $a^{13} \mathrm{C}$ urea breath test. Also, the fasting gastrin concentrations were measured before and after treatment for $H$ pylori infection.
\end{abstract}

Results-Cure of $H$ pylori infection resulted in a considerable improvement in both antral and corpus gastritis and a decrease in fasting gastrin concentrations. As a result of the cure the night time intragastric pH during treatment with ranitidine decreased (median pH $6.8 v 5.4$; $p=0 \cdot 007$, whereas the acidity during the daytime was not affected.

Conclusions-In patients with duodenal ulcer the intragastric pH during treatment with ranitidine depends on $H$ pylori. However, the loss of effectiveness in altering pH seems to be less pronounced than previously found with omeprazole.

(Gut 1997; 41: 33-36)

Keywords: Helicobacter pylori; intragastric acidity; omeprazole; ranitidine

We have previously shown that the $\mathrm{pH}$ response to omeprazole decreases after curing a Helicobacter pylori infection, both in healthy volunteers and in patients with a duodenal ulcer. ${ }^{12}$ This apparent loss of effectiveness is paralleled by the disappearance of acid neutralising ammonia produced by $H$ pylori. ${ }^{34}$ It is conceivable that the neutralising effect of ammonia would become more evident if the $\mathrm{H}^{+}$concentration in the gastric juice is low. This could explain why, after cure of the infection, the $\mathrm{pH}$ falls during omeprazole treatment but does not change in the spontaneously secreting stomach. ${ }^{1}$ Although we have presented evidence for such a neutralising system, other possible mechanisms come to mind. Firstly, it is well established that the severity of corpus gastritis increases during omeprazole treatment, interfering with acid secretion. ${ }^{5}{ }^{6}$ Secondly, omeprazole is a prodrug which is activated in secreting parietal cells. If before the cure the proportion of secreting parietal cells was higher than after the cure, then less omeprazole would be activated after the cure. This would lead to a loss of effectiveness of the drug. One way to investigate such mechanisms is the use of a secretory inhibitor which is not activated in the parietal cells and to compare the results of such a drug with the omeprazole data. We therefore gave ranitidine to patients with duodenal ulcer before and after cure of $H$ pylori infection.

\section{Methods}

STUDY POPULATION

Patients with an endoscopically established duodenal ulcer associated with $H$ pylori infection and aged over 18 years were eligible for the study. Exclusion criteria were pretreatment with antisecretory drugs, sucralfate, bismuth compounds, or antibiotics during the previous four weeks, pregnancy or lactation, severe concomitant diseases, additional gastric ulcer or reflux oesophagitis, or a history of stomach surgery, except simple closure of a perforation, and a suspected lack of compliance (for example, alcohol or drug misuse). The study was conducted according to the Declaration of Helsinki. All patients gave written informed consent. The protocol was approved by the ethics committee of the University of Essen.

\section{STUDY DESIGN}

Before enrolment and four to six weeks after cessation of the anti- $H$ pylori treatment, patients were investigated clinically and endoscopically. Four antral and four corpus biopsy specimens were assessed for $H$ pylori using a rapid urease test (HUT test, Astra GmbH, Wedel, Germany), specific culture, histology (Warthin Starry stain), and the ${ }^{13} \mathrm{C}$ urea breath test.

A 24 hour $\mathrm{pH}$ measurement was performed on day 8 of a course of ranitidine $(300 \mathrm{mg}$ at 2100) before the treatment for $H$ pylori infection. Ranitidine treatment was followed by one week of $H$ pylori treatment. Ulcer healing and cure of $H$ pylori infection were 
checked four to six weeks after cessation of all medication. A final $\mathrm{pH}$ recording was then performed on day 8 of a second course of ranitidine $(300 \mathrm{mg}$ at 2100$)$.

TREATMENT FOR HELICOBACTER PYLORI

All patients were treated with omeprazole (40 mg twice daily), amoxicillin ( $1 \mathrm{~g}$ twice daily), and clarithromycin (500 mg twice daily) for one week.

24 HOUR PH-METRY

After an overnight fast, a glass $\mathrm{pH}$ electrode (Ingold 440-M3, Medical Instruments Corporation, Solothurn, Switzerland) was inserted transnasally and placed $5 \mathrm{~cm}$ below the cardia. The correct position was controlled fluoroscopically. The $\mathrm{pH}$ recordings were performed as previously described. ${ }^{1}$ Patients took ranitidine $(300 \mathrm{mg})$ at 2100.

\section{ASSESSMENT OF HELICOBACTER PYLORI INFECTION}

During each endoscopy four biopsy specimens were taken from both the lesser curvature of the proximal antrum and the greater curvature of the proximal body of the stomach. These were analysed by a rapid urease test, specific culture under microaerophilic conditions for three to five days, and histology using haematoxylin and eosin and Warthin and Starry stains to grade the gastritis and $H$ pylori density. ${ }^{78}$ The urea breath test was performed with $75 \mathrm{mg}{ }^{13} \mathrm{C}$-labelled urea and orange juice as a test meal. ${ }^{9}$ An excess $(>4 \%)$ was considered to be positive for $H$ pylori infection. We defined cure of the $H$ pylori infection as no evidence of persistant colonisation of the gastric mucosa by any method four to six weeks after cessation of the $H$ pylori treatment.

GASTRIN ANALYSIS

Fasting gastrin concentrations were measured by radioimmunoassay (Diagnostic Products Corporation, Bad Nauheim, Germany) before and four to six weeks after the cure of the $H$ pylori infection.

DATA ANALYSIS

The time intervals for the analysis of the $\mathrm{pH}$ recordings were predefined as follows: entire recording (0900-0900), combined postprandial periods (0930-1130, 1330-1530, 1930-2130), night time (2200-0600), and the remaining combined non-meal daytime period. Median $\mathrm{pH}$ values as well as the percentage of time spent at $\mathrm{pH} \geq 3$ were calculated for the entire recording and each of the time windows. Mean $\mathrm{H}^{+}$concentrations $(\mathrm{h} \times \mathrm{mmol} / \mathrm{l})$ were calculated from the raw $\mathrm{pH}$ values with "pack 3" software (Medical Instruments Corporation). All data are given as group median values with the interquartile range. Statistical comparisons were made using the Wilcoxon signed rank test for paired samples.
The gastritis scores and the urea breath test results before and after treatment were compared statistically with the two tailed Wilcoxon signed rank test for paired samples. Significance was considered at a $5 \%$ probability level.

\section{Results}

Eighteen patients (median age (range) 44 (23-75) years; 14 men; 11 current smokers) with relapsing duodenal ulcer disease associated with an $H$ pylori infection were studied. The infection was cured in all patients as judged from negative bacterial findings by all four methods four to six weeks after cessation of treatment. All ulcers had healed at the time of follow up endoscopy. The elimination of $H$ pylori infection was associated with a highly significant decrease in the total scores of both antral (11 (range 9-14) v 3 (1-5); $\mathrm{p}<0.0001$ ) and body gastritis (5 (1-14) v 1 (1-2); $\mathrm{p}<0.0001)$ and the fasting gastrin concentrations $(64.5(34-158) \mathrm{pg} / \mathrm{ml} v 41.0(19-84)$ $\mathrm{pg} / \mathrm{ml}, \mathrm{p}<0.0001)$.

During treatment with ranitidine the median intragastric $\mathrm{pH}$ was higher at night time before $H$ pylori treatment than four to six weeks after the infection was cured, whereas the combined postprandial $\mathrm{pH}$ and the non-meal daytime $\mathrm{pH}$ remained unchanged (fig 1 ; table 1 ). There was only a trend towards a higher mean $\mathrm{H}^{+}$activity after cure of $H$ pylori infection (table 1 ). The time spent with $\mathrm{pH}$ values $\geq 3$ and $\geq 4$ was greater before $H$ pylori treatment than after cure of the infection during the entire recording period and at night (table 1).
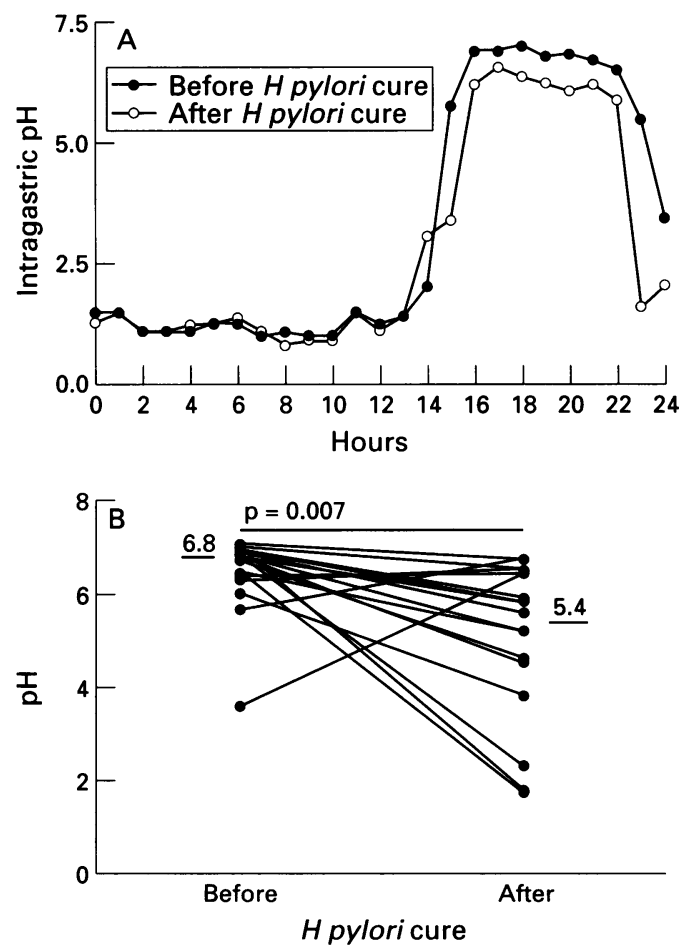

Figure 1: Median 24 hour $p H$ curves $(A)$ and individual night time intragastric $p H(B)$ during treatment with $300 \mathrm{mg}$ ranitidine (2100) before and after the elimination of $\mathrm{H}$ pylori infection in patients with duodenal ulcer. pH recordings started at 0900 hours. 
TABLE 1 Intragastric acidity during treatment with ranitidine ( $300 \mathrm{mg}$ ) at night before and after treatment for $\mathrm{H}$ pylori infection in patients with duodenal ulcer

\begin{tabular}{|c|c|c|c|}
\hline & Before treatment & After treatment & $p$ Value \\
\hline \multicolumn{4}{|l|}{ Median gastric $\mathrm{H}(\mathrm{IQR})$ : } \\
\hline 24 hours & $2 \cdot 0(1 \cdot 8-2 \cdot 1)$ & $1 \cdot 5(1 \cdot 3-2 \cdot 1)$ & $0 \cdot 13$ \\
\hline Daytime & $1 \cdot 3(1 \cdot 2-1 \cdot 6)$ & $1 \cdot 2(1 \cdot 0-1 \cdot 6)$ & $0 \cdot 26$ \\
\hline Postprandial & $1 \cdot 4(1 \cdot 1-1 \cdot 5)$ & $1 \cdot 2(1 \cdot 2-1 \cdot 4)$ & $0 \cdot 18$ \\
\hline Night time & $6 \cdot 8(6 \cdot 4-6 \cdot 9)$ & $5 \cdot 4(4 \cdot 5-6 \cdot 4)$ & $0 \cdot 007$ \\
\hline \multicolumn{4}{|l|}{ Median $\mathrm{H}^{+}(\mathrm{h} \times \mathrm{mmol} / \mathrm{l})(\mathrm{IQR})$ : } \\
\hline $\begin{array}{l}24 \text { hours } \\
\text { Median time }(\%)>\mathrm{pH} 3(\mathrm{IQR}) \text { : }\end{array}$ & $44 \cdot 3(36 \cdot 6-50 \cdot 4)$ & $58 \cdot 4(35 \cdot 5-72 \cdot 3)$ & $0 \cdot 14$ \\
\hline 24 hours & $42 \cdot 8(38 \cdot 8-44 \cdot 9)$ & $32 \cdot 0(28 \cdot 5-41 \cdot 5)$ & 0.02 \\
\hline Median time $(\%)>\mathrm{pH} 4(\mathrm{IQR})$ : & $84 \cdot 1(74 \cdot 0-92 \cdot 8)$ & $74 \cdot 2(60 \cdot 3-80 \cdot 5)$ & $0 \cdot 04$ \\
\hline $\begin{array}{l}24 \text { hours } \\
\text { Night time }\end{array}$ & $\begin{array}{l}38 \cdot 8(33 \cdot 4-41 \cdot 7) \\
79 \cdot 4(73 \cdot 6-85 \cdot 0)\end{array}$ & $\begin{array}{l}27 \cdot 3(23 \cdot 5-34 \cdot 9) \\
62 \cdot 8(53 \cdot 9-74 \cdot 9)\end{array}$ & $\begin{array}{l}0.006 \\
0.04\end{array}$ \\
\hline
\end{tabular}

$\mathrm{IQR}=$ Interquartile range. after cure would be more pronounced with omeprazole than with ranitidine. This could explain the apparent conservation of the effectiveness of ranitidine after cure. Fourthly, acid secretion depends on the severity of corpus gastritis, ${ }^{6}{ }^{13}$ possibly mediated by cytokines such as interleukin-1. ${ }^{17-19}$ As the severity of corpus gastritis increases during treatment with omeprazole, this could account for the more pronounced augmentation of the $\mathrm{pH}$ raising effect in infected subjects. However, despite further improvement of the corpus gastritis during a one year follow up the $\mathrm{pH}$ response to omeprazole remained unchanged, both in healthy subjects and in patients with duodenal ulcer. ${ }^{20}{ }^{21}$ Moreover, the severity of gastritis did not correlate with the magnitude of $\mathrm{H}^{+}$concentration change induced by omeprazole. ${ }^{21}$ Therefore, it is less likely that changes in gastritis play a major part.

A weakness of our studies is that we cannot exclude differences in the intragastric $\mathrm{pH}$ in the spontaneously secreting stomach, neither between the study groups treated with omeprazole and ranitidine, nor within the study groups before and after the cure. However, we have shown that cure of $H$ pylori infection does not affect the intragastric $\mathrm{pH}$ without treatment, both in healthy subjects and in patients with duodenal ulcer. ${ }^{121}$ Nevertheless, in future studies it will be necessary to give ranitidine in doses which also inhibit acid secretion during the day and omeprazole to the same patients before and after cure of $H$ pylori infection, to make morphological assessments of resting and activated parietal cells before and after the cure, and to test other secretory inhibitors which are or are not given as prodrugs and activated in the parietal cell.

In conclusion, we have provided evidence that the effect of $H$ pylori on the intragastric $\mathrm{pH}$ in response to ranitidine is small. The present study may have clinical implications. It will be important in the future to assess, for all secretory inhibitors, to what extent they lose their ability to raise intragastric $\mathrm{pH}$ in patients cured of $H$ pylori infection. Whereas histamine antagonists are - compared with proton pump inhibitors - relatively weak secretory inhibitors, they may have the advantage of being comparably effective before and after cure of infection. It might be interesting to compare the effectiveness of ranitidine and omeprazole in patients with reflux oesophagitis after stratification for $H$ pylori. histamine, which is a potent secretagogue and inhibitor of antral somatostatin release. ${ }^{15}$ This may accelerate the transformation of omeprazole into the active sulphenamide. In the case of ranitidine such activation does not take place and therefore ranitidine would be as effective before as after the cure. Thirdly, omeprazole, by contrast with ranitidine, also inhibited acid secretion during the day. This continous inhibition is known to lead to more dense colonisation of the proximal part of the stomach with $H$ pylori. ${ }^{5} 16$ The colonisation of the fundus and proximal corpus with $H$ pylori determines the concentration of neutralising substances, such as ammonia, at the site of the electrode; the fall in neutralising substances
1 Labenz J, Tillenburg B, Peitz U, Idström J-P, Verdú EF Stolte $\mathrm{M}$, et al. Helicobacter pylori augments the $\mathrm{pH}$ increasing effect of omeprazole in patients with duodenal ulcer. Gastroenterology 1996; 110: 725-32. Dorta G, et al. Effect of curing Helicobacter pylori infection on intragastric $\mathrm{pH}$ during treatment with omeprazole. Gut 1995; 37: 743-8.

3 Goggin PM, Marrero JM, Ahmed H, Jackson PA Corbishley SM, Northfield TC. Urea hydrolysis in Helicobacter pylori infection. Eur $\mathcal{f}$ Gastroenterol Hepatol 1991; 3: 927-33. Lieber ChS. Severity of Helicobacter-induced gastric injury correlates with gastric juice ammonia. Dig Dis $S c i$ 1991; 36: 1089-96.

5 Logan RP, Walker MM, Misiewicz JJ, Gummett PA, distribution of Helicob. Changes in the intragastric omeprazole. Gut 1995; 36: 12-6.
2 Verdú E, Armstrong D, Idström J-P, Labenz J, Stolte $M$

4 Triebling AT, Korsten MA, Dlugosz JW, Paronetto F 
6 Feldman M, Cryer B, McArthur KE, Lee E. Relationship between severity of $\mathrm{H}$ pylori (HP) gastritis and gastric acid-pepsin secretion in man. Gastroenterology 1996; 110: A 106 .

7 Labenz J, Stolte $M$, Aygen S, Hennemann O, Bertrams J, Börsch G. Qualitative and semiquantitative invasive and non-invasive assessment of Helicobacter pylori colonisation of the gastric mucosa. $Z$ Gastroenterol 1993; 31: 437-43.

8 Stolte M, Stadelmann O, Bethke B, Burkard G. Relationships between the degree of Helicobacter pylori ships between the degree of Helicobacter pylori
colonisation and the degree and activity of gastritis, colonisation and the degree and activity of gastritis, Garface epithelial degeneration,

9 Labenz J, Aygen S, Hennemann O, Stolte M, Becker T, Peitz U, Börsch G. Correlation of ${ }^{13} \mathrm{CO}_{2}$ excess with Helicobacter pylori density, grade and activity of gastritis. Gastroenterology 1995; 108: A139.

10 Bercik P, Verdú EF, Armstrong D, Cederberg C, Idström J-P, Stolte $M$, Blum AL. H pylori related increase in omeprazole (OME) effect is associated with ammonia production. Gastroenterology 1996; 110: A64.

11 Noach LA, Bosma NB, Jansen J, Hoek FJ, van Deventer SJ, Tytgat GN. Mucosal tumor necrosis factor- $\alpha$, interleukin$1 \beta$, and interleukin- 8 production in patients with Helicobacter pylori infection. Scand $\mathcal{F}$ Gastroenterol 1994; 29: 425-9.

12 Peek RM, Miller GG, Tham KT, Perez-Perez GI, Zhao X, Atherton JC, Blaser MJ. Heightened inflammatory response and cytokine expression in vivo to cagA+

13 Yasunaga Y, Shinomura Y, Kanayama S, Higashimoto Y Yabu $M$, Nakanishi $T$, et al. Increased fundic mucosal interleukin- $1 \alpha$ and hepatocyte growth factor release in $\mathrm{H}$ pylori associated enlarged fold gastritis. Gastroenterology 1995; 108: A263.

14 Prinz C, Schepp W, Classen M, Zeng N-X, Sachs G. Interleukin and EGF/TGF $\alpha$ effects on isolated rat enterochromaffin-like cells. Gastroenterology 1995; 108: A196.

15 Courillon-Mallet A, Launay J-M, Roucayrol A-M Callebert J, Emond J-P, Tabuteau F, Cattan D. Helicobacter pylori infection: physiopathologic implication of $\mathrm{N}^{\alpha}$-methylhistamine. Gastroenterology 1995; 108: 959-66.

16 Stolte $M$, Bethke B. Elimination of Helicobacter pylori under treatment with omeprazole. $Z$ Gastroenterol 1991; 28: $271-4$

17 Esplugues JV, Barrachina MD, Calatayud S, Pique JM, Whittle BJ. Nitric oxide mediates the inhibition by interleukin- $1 \beta$ of pentagastrin-stimulated rat gastric acid secretion. Br f Pharmacol 1993; 108: 9-10.

18 Robert A, Olafsson AS, Lancaster C, Zhang WR Interleukin-1 is cytoprotective, antisecretory, stimulates PGE2 synthesis by the stomach, and retards gastric emptying. Life Sci 1991; 48: 123-34.

19 Taché Y, Saperas E. Potent inhibition of gastric acid secretion and ulcer formation by centrally and peripherally administered interleukin-1 $\alpha$. Ann NY Acad Sci 1992; 664: 353-68.

20 Labenz J, Tillenburg B, Peitz U, Idström J-P, Verdú E, Stolte $M$, et al. Irreversible fall of efficacy of omeprazole (OME) after cure of $\mathrm{H}$ pylori (HP) infection in duodenal ulcer (DU) patients. Gastroenterology 1996; 110: A166.

21 verdú EF, Armstrong D, Idström J-P, Labenz J, Stolte M Börsch G, Blum AL. Intragastric pH during treatment Börsch $\mathrm{G}$, Blum $\mathrm{AL}$. Intragastric $\mathrm{pH}$ during treatment
with omeprazole: role of Helicobacter pylori and $\mathrm{H}$ pyloriwith omeprazole: role of Helicobacter pylori and $\mathrm{H}$ pyloriassociated 